\title{
A More Reliable Method for Monitoring the Condition of Three-Phase Induction Motors Based on Their Vibrations
}

\author{
R. Shnibha, A. Albarbar, A. Abouhnik, and G. Ibrahim \\ Advanced Industrial Diagnostic Centre, School of Engineering, Manchester Metropolitan University, Manchester M1 5GD, UK
}

Correspondence should be addressed to R. Shnibha, rshnibh@yahoo.com

Received 15 June 2012; Accepted 4 September 2012

Academic Editors: C. Del Vecchio and A. E. Huespe

Copyright () 2012 R. Shnibha et al. This is an open access article distributed under the Creative Commons Attribution License, which permits unrestricted use, distribution, and reproduction in any medium, provided the original work is properly cited.

This paper is concerned with accurate, early, and reliable fault diagnosis using an enhanced vibration measurement technique based on short-time Fourier transform. The novelty of this work lies in detecting very low-phase imbalance-related faults. The energy contained within specified frequency bands centred on the rotor frequency and power supply frequency, and their sideband zones were calculated. The technique was firstly demonstrated by simulated signals and then verified by experimental measurements taken from two different-sized test rigs. The first one comprised a $1.1 \mathrm{~kW}$ variable speed three-phase induction motor with varying output load (no load, 25\%, 50\%, 75\%, and 100\% load). Two types of common faults were introduced: imbalance in one phase as the electrical fault and misalignment of load as the mechanical fault. The second test rig had a $3 \mathrm{~kW}$ three-phase induction motor again with varying load, and here the two seeded faults were: phase imbalance and one broken rotor bar. The measured energy levels in the test conditions were found to be affected by type of fault and fault severity. It is concluded that the proposed method offers a potentially reliable and computationally inexpensive condition monitoring tool which can be implemented with real-time monitoring systems.

\section{Introduction}

Condition-monitoring and condition-based maintenance aim at increasing machine reliability, maintaining performance, reducing spare parts inventories, and reducing breakdown maintenance. Induction motors are common prime movers and faults including winding faults, unbalanced stator and, broken rotor bars, eccentricity, and bearing faults have been extensively studied [1].

All induction motors generate noise and vibration, and analysis of these can be used to give information on the condition of the motor. Noise and vibration in induction motors are caused by forces which are of magnetic, mechanical, and aerodynamic origin. The largest sources of vibration and noise in induction motors are the radial forces due to the air gap field because the air gap flux density distribution is a product of the resultant mmf wave and the total permeance wave. The resultant magneto motive force, $\mathrm{mmf}$, also contains the effect of possible rotor or stator asymmetries, and the permeance wave depends on the variation of the air gap as the resulting magnetic forces also depend on these asymmetries. Thus by analysing the vibration signal of an induction motor, it is possible to detect various types of faults and asymmetries. There have been many practical demonstrations of the capability of vibration monitoring to detect a wide range of motor faults; these include shaft eccentricity/misalignment [2,3], bearing faults [3], looseness [4], rotor imbalance [5], and broken rotor bar [3-6].

The vibration of either the motor stator core or end caps can be easily monitored by an accelerometer which is usually directly mounted on the motor. Analysing the measured signal using conventional signal processing techniques such as fast Fourier transforms (FFTs) does not always achieve adequate results. When looking at a Fourier transform of a signal, it is impossible to tell when a particular event took place. In an effort to determine when and at what frequencies a signal event occurred, Darowicki and Zieliński [7] derived the short-time Fourier transform (STFT) based on application of a time window to localise the spectrum in the time domain. 


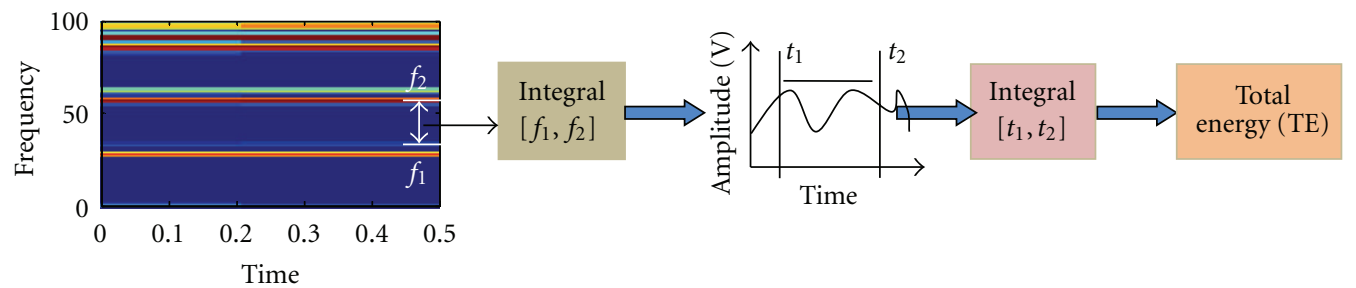

FIGURE 1: Schematic representation of calculation of total energy.

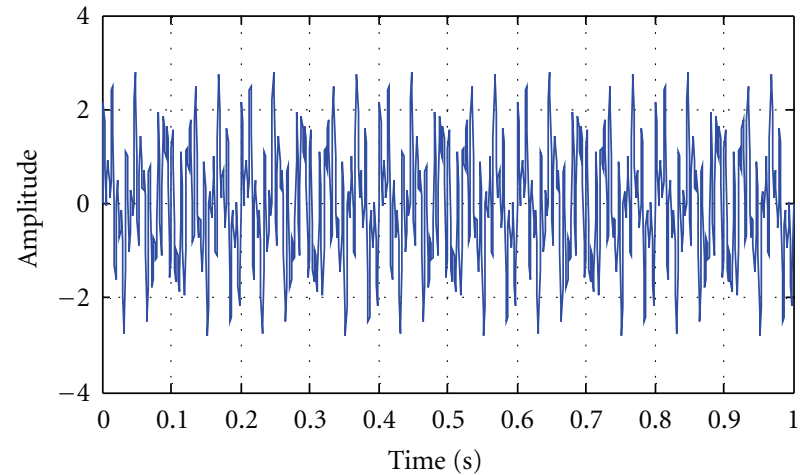

(a)

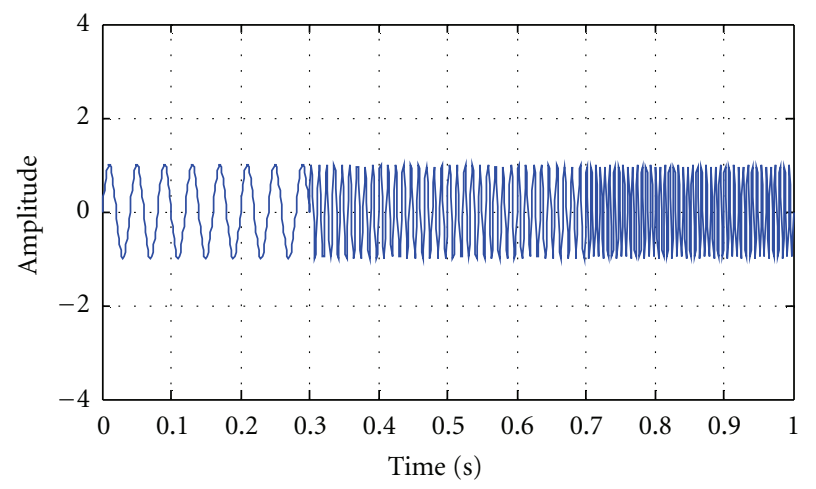

(c)

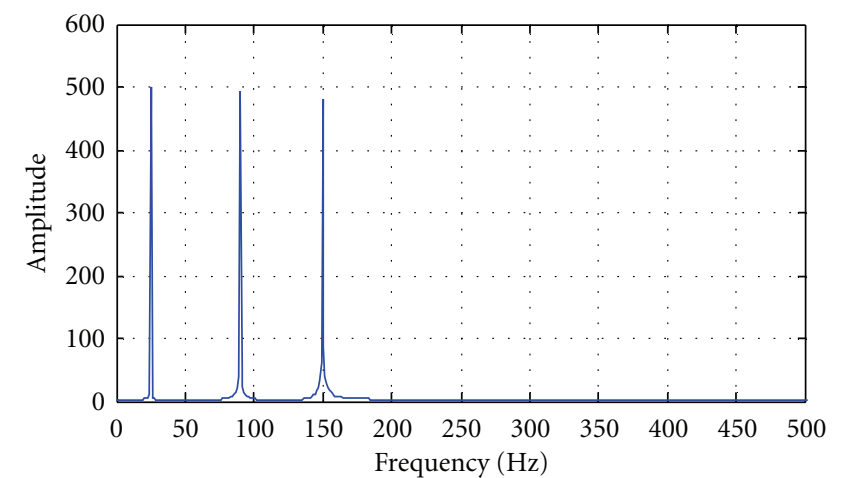

(b)

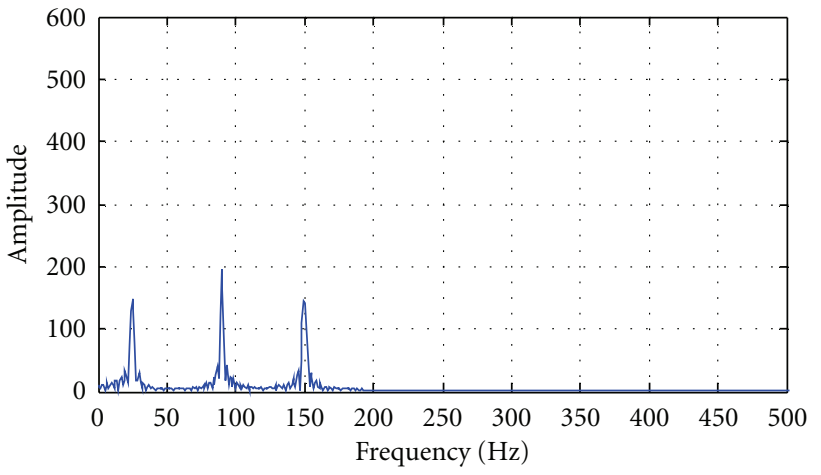

(d)

Figure 2: Time- and frequency-domain representations of the two signals $f_{1}$ and $f_{2}$. (a) $f_{1}$ in time domain, (b) $f_{1}$ in frequency domain, (c) $f_{2}$ in time domain, and (d) $f_{2}$ in frequency domain.

Jurado and Saenz [8] showed that the discrete STFT is suitable for harmonic analysis and by selecting a small window length was able to detect transients within noisy data. Arabaci and Bilgin [9] showed experimentally that using the STFT for fault diagnosis and classification in induction motors, where the faults were broken rotor bars and broken end rings, increased accuracy rates.

\section{Conventional Methods and the Proposed Technique}

2.1. The Proposed Method. Most condition monitoring to detect damage in the induction motor focuses on statistical analysis of the time-domain signal. RMS, crest factor (CF), and kurtosis are parameters that have been widely used. Each parameter has been defined in detail in $[10,11]$. However, the method proposed here is based on using the STFT and subsequently calculating the energy contained within certain frequency bands and their sideband zones. Equation (1) mathematically expresses this novel method:

$$
\mathrm{TE}=\int_{t_{1}}^{t_{2}} \int_{f_{1}}^{f_{2}} \operatorname{STFT}(t, f) d f d t,
$$

where TE is the total energy level in the frequency band, and $f_{1}$ and $f_{2}$ are the lower and upper frequency boundaries, respectively. In this study, integration is calculated using the trapezoid rule. As a first step, energy is calculated per unit time using MATLAB, obtaining numerical values for energy as a function of the time. In the second step the trapezoid rule is applied to find total energy of the signal spectrum. To help in understanding the first and second steps [12], the process is illustrated in Figure 1. 


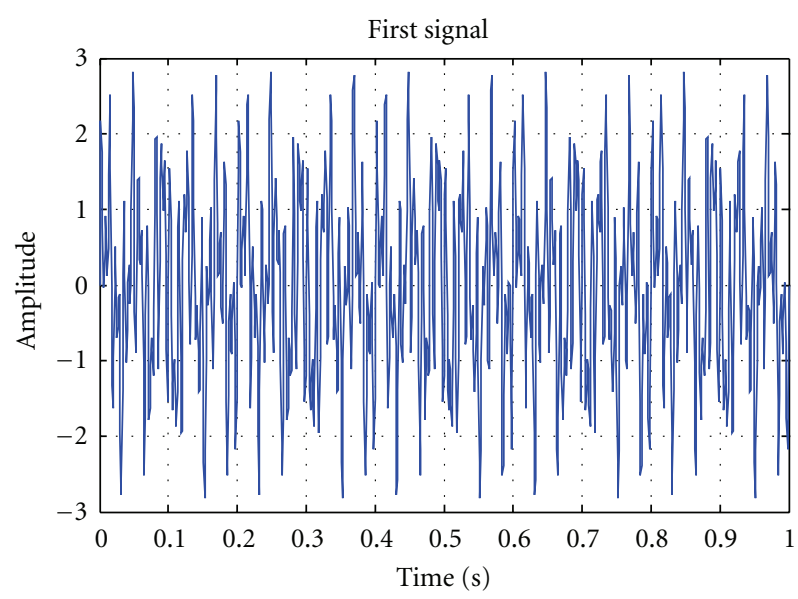

(a)

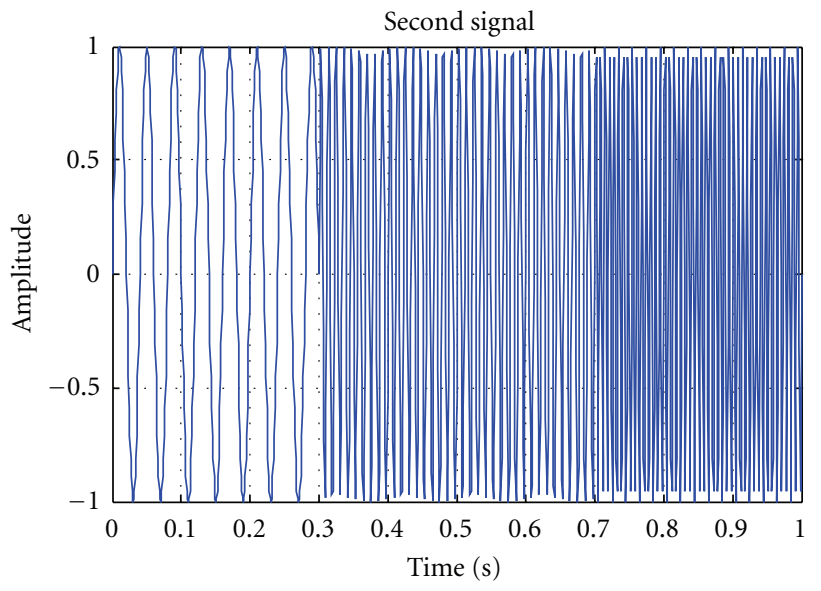

(c)

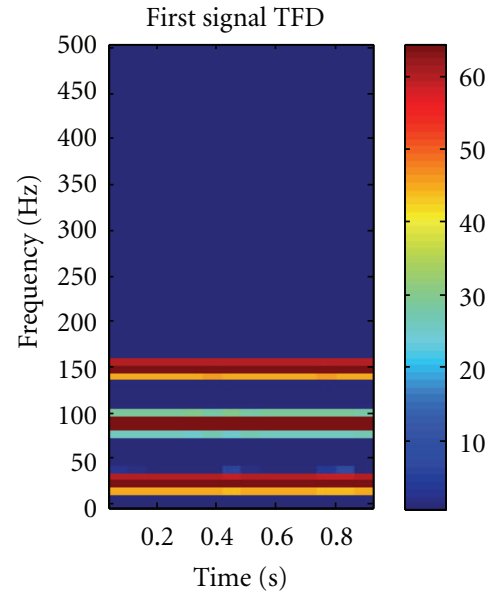

(b)

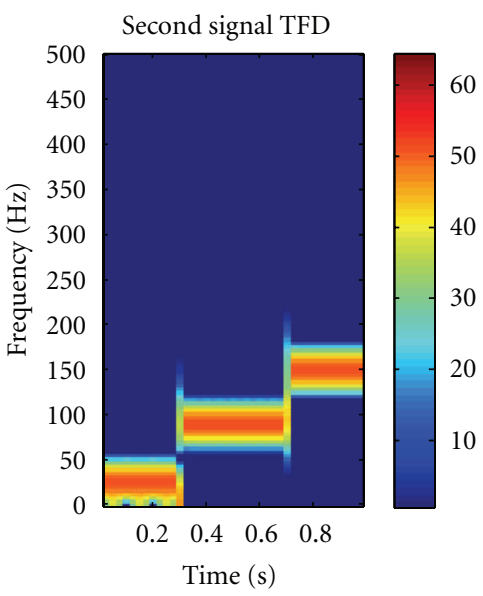

(d)

FIgURE 3: Time- and frequency-domain representations of the two signals $f_{1}$ and $f_{2}$ : (a) $f_{1}$ time domain, (b) $f_{1}$ time frequency-domain, (c) $f_{2}$ time domain, and (d) $f_{2}$ time-frequency domain.

2.2. Numerical Simulation. Conventional analysis, using statistical parameters and the Fourier transform of a periodic, stationary, and deterministic signal, cannot take into account the temporal variation of the spectral characteristics of a nonstationary signal. Consider the two signals shown in Figure 2. The first signal is represented in (2):

$$
f_{1}(t)=\sin (2 \pi \cdot 25 t)+\sin (2 \pi \cdot 90 t)+\sin (2 \pi \cdot 150 t) .
$$

This signal contains three sinusoids of equal amplitudes and frequencies 25,90 , and $150 \mathrm{~Hz}$; therefore, it can be described as a stationary signal. Figure 2(a) represents a $1000 \mathrm{~ms}$ period of this signal, and its frequency spectrum is shown in Figure 2(b).

A nonstationary signal $f_{2}$ contains the same frequency components as $f_{1}$ but in three discrete and different time intervals. A $1000 \mathrm{~ms}$ length of this signal is plotted in Figure 2(c), and its spectrum is plotted in Figure 2(d). The time interval from 0 to $350 \mathrm{~ms}$ contains a $25 \mathrm{~Hz}$ sinusoid, the interval from 350 to $700 \mathrm{~ms}$ contains a $90 \mathrm{~Hz}$ sinusoid, and the interval from 700 to $1000 \mathrm{~ms}$ contains a $150 \mathrm{~Hz}$ sinusoid as described in (3).
Consider

$$
f_{2}(t)= \begin{cases}\sin (2 \pi * 25 t), & 0 \leq t \leq 350 \\ \sin (2 \pi * 90 t), & 350 \leq t \leq 700, \\ \sin (2 \pi * 150 t), & 350 \leq t \leq 1000\end{cases}
$$

Consider the signals represented by (2) and (3) and presented in Figure 2. Both signals are composed of the same three frequency components, but while $f_{1}(t)$ shown in Figure 2(a) contains all three signals for the entire time interval, $f_{2}(t)$ shown in Figure 2(c) contains the individual components for different time intervals. The time-domain representations are completely different. However, the frequency domains shown in Figures 2(b) and 2(d) obtained using the FFT are essentially identical because the FFT does not provide information on the time when spectral components are present. In this sense the FFT is not a suitable technique for nonstationary signals.

To accurately represent the frequency information contained in a nonstationary signal, a transform that presents both time and frequency information is needed to produce a signal spectrum in the time-frequency domain, preferably 


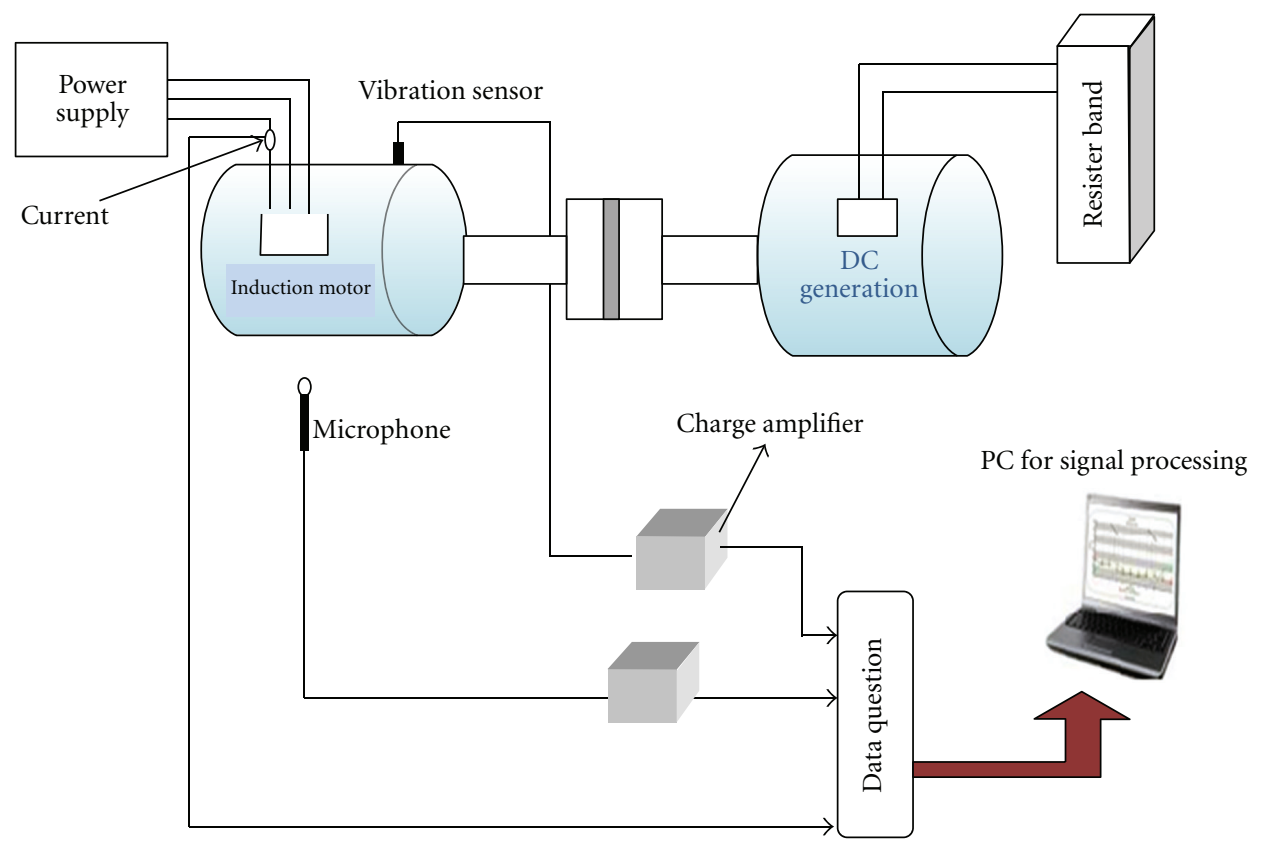

FIGURE 4: Schematic diagram of induction motor test rig.

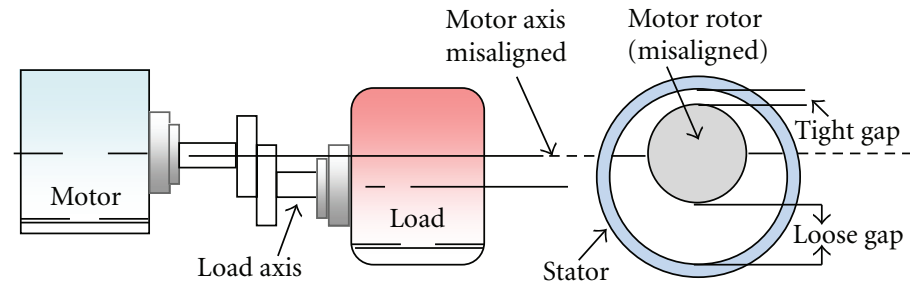

Figure 5: Motor offset misalignment [13].

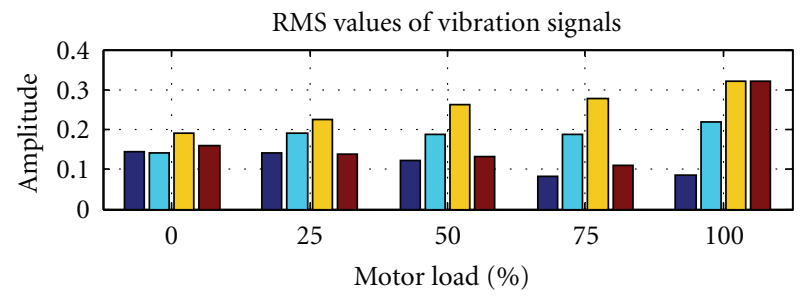

(a)

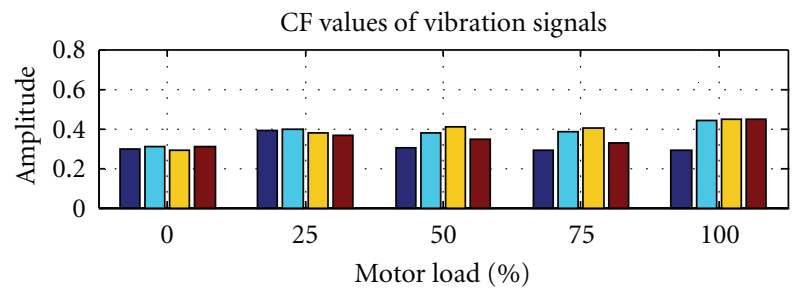

(b)

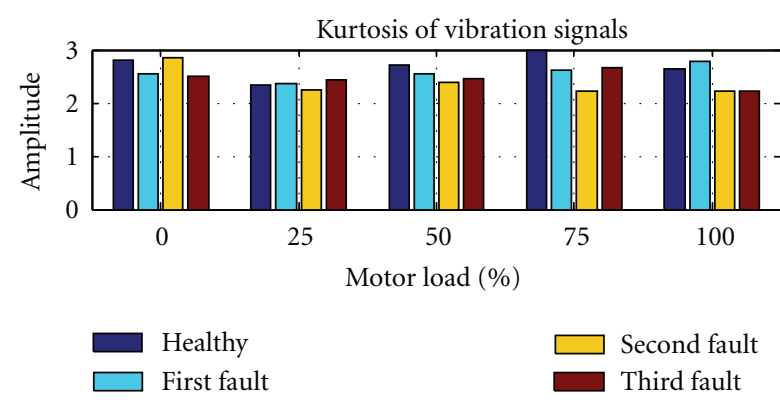

(c)

FIGURE 6: Statistical parameters from the time domain of the vibration signal. 


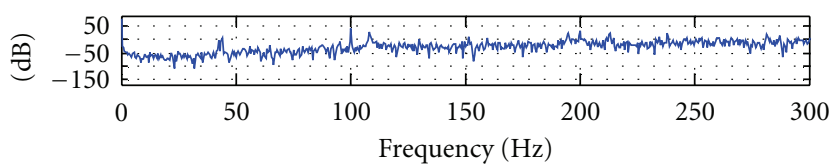

(a)

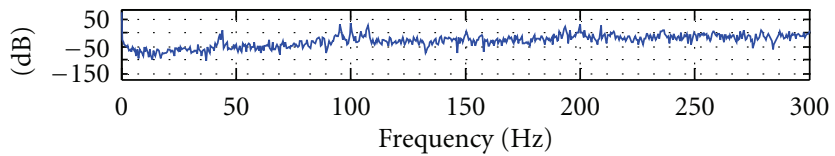

(c)

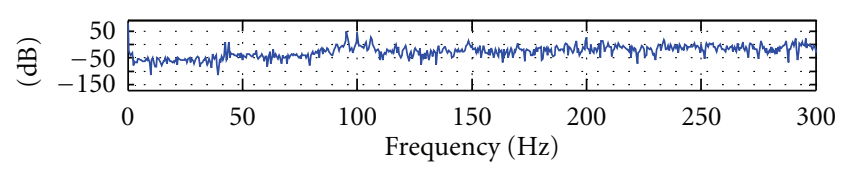

(e)

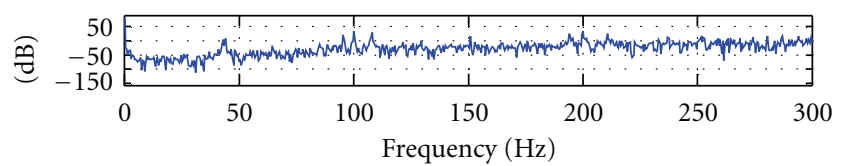

(b)

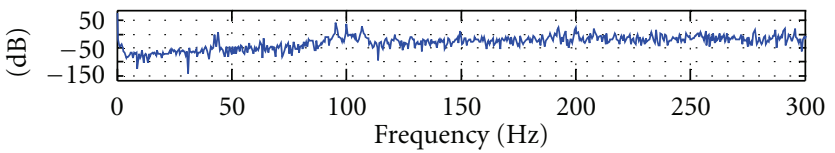

(d)

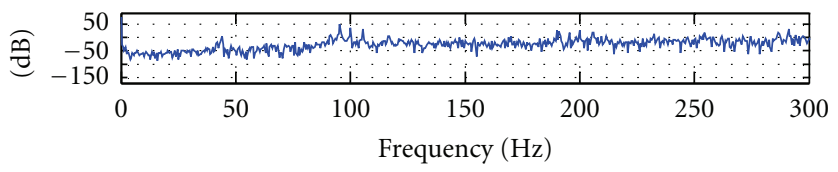

(f)

FIGURE 7: Measured frequency domain of vibration signal with voltage imbalance in one phase of the supply, at $100 \%$ load.

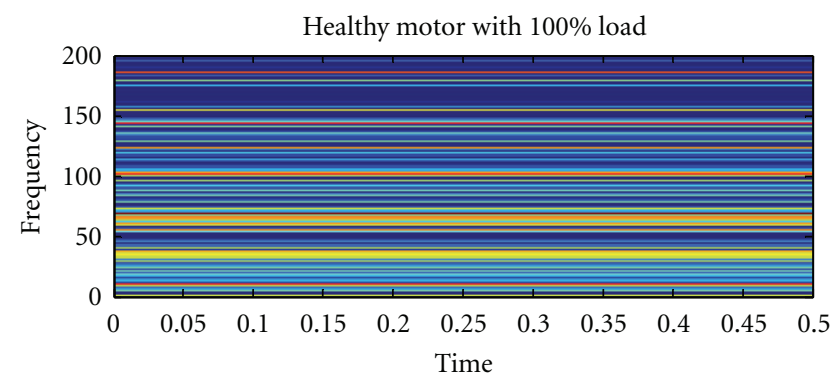

(a)

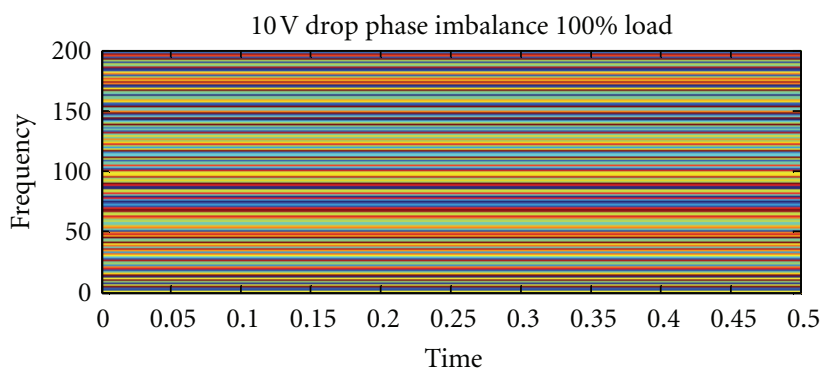

(c)

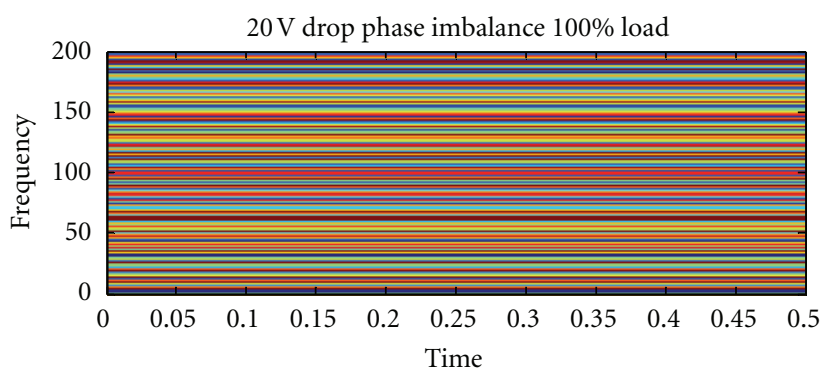

(e)

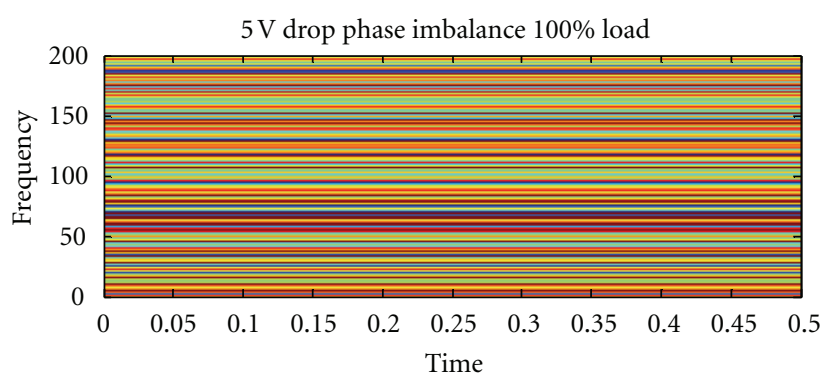

(b)

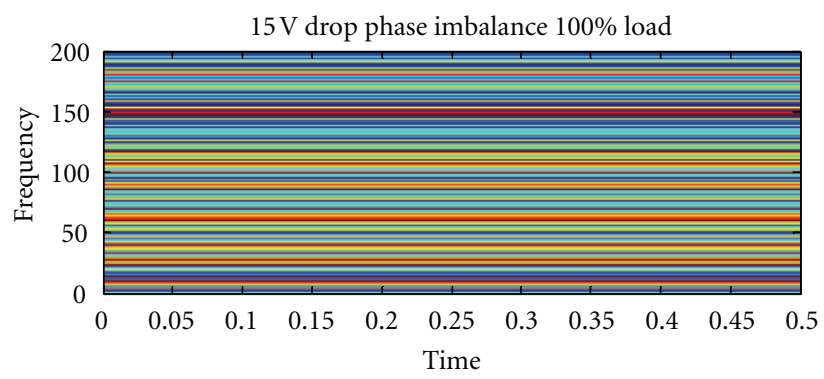

(d)

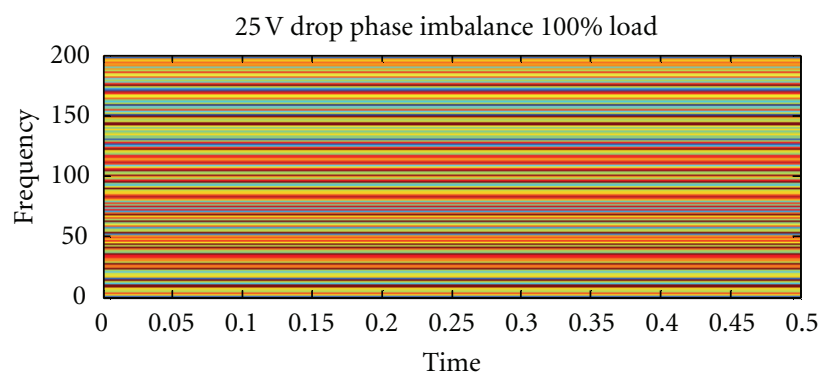

(f)

FIGURE 8: STFT of vibration signals from $1.1 \mathrm{~kW}$ motor with various voltage imbalances in one phase of the supply, $1500 \mathrm{rpm}$ and $100 \%$ load. 


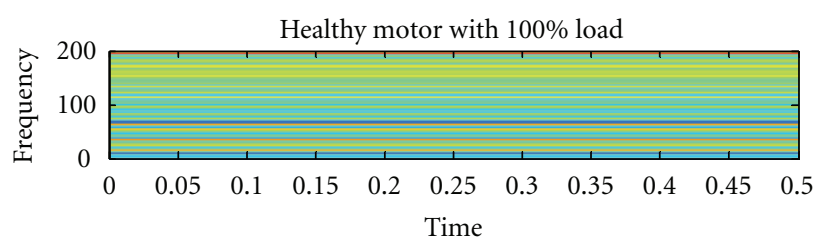

(a)

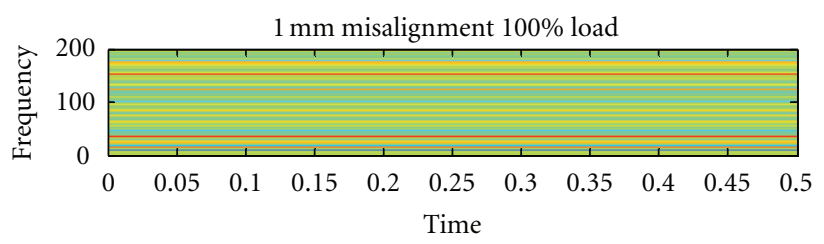

(b)

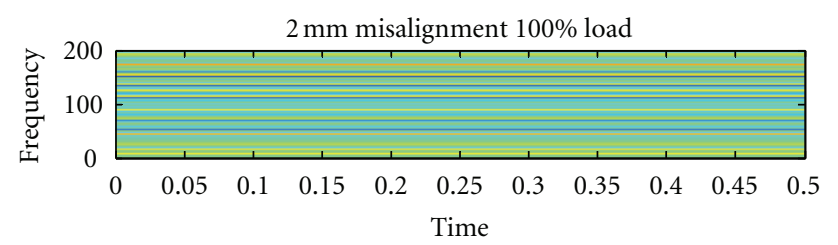

(c)

FigURE 9: STFT of vibration signals from $1.1 \mathrm{~kW}$ motor with $1 \mathrm{~mm}$ and $2 \mathrm{~mm}$ misalignment faults, $1500 \mathrm{rpm}$ and $100 \%$ load.

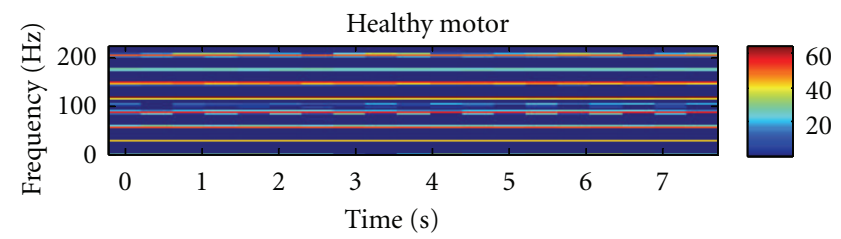

(a)

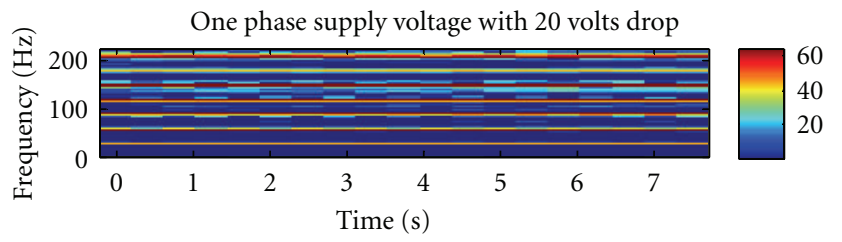

(b)

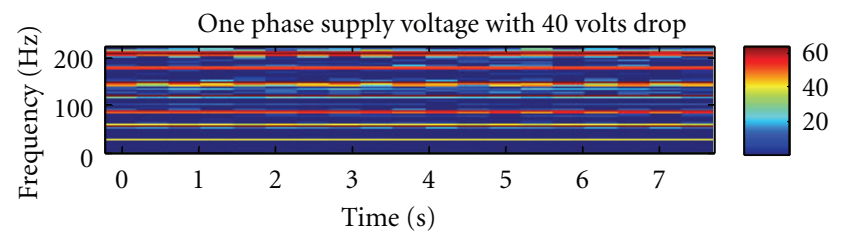

(c)

FIGURE 10: STFT of vibration signal from $3 \mathrm{~kW}$ motor with various voltages imbalances in one phase of the supply, $1500 \mathrm{rpm}$ and $75 \%$ load.

in a manner which plots the amplitudes against time and frequency as shown in Figure 3.

Using such a technique to analyse transient, nonstationary, and vibration signals emitted by electromechanical machinery theoretically enables every event observed in the time-frequency domain to be linked to its source. Provided that the sources can be separated in the frequency domain it should be possible to quantify the vibration energy associated with each event. This energy can then be evaluated with respect to that obtained for a healthy machine.

An efficient time-frequency method should

(1) analyse the frequencies associated with each source of excitation,

(2) identify at each point of the structure the response to each source of excitation, and

(3) measure the contribution of each source of excitation in terms of its energy.

\section{Instrumentation and Data Collection}

A schematic diagram of the test rig and instrumentations is shown in Figure 4. It comprised a $1.1 \mathrm{~kW}$ variable speed induction motor, a DC generator and a resistor bank to act as a load. The instrumentation consisted of an accelerometer B\&K type 4371 . The accelerometer was positioned vertically on the drive end using superglue (Figure 4). The output of the accelerometer was filtered and amplified via a charge amplifier. The measured data was then transferred to the computer using 24-bit resolution data acquisition. The sampling frequency was $50 \mathrm{kHz}$. The developed Labviewbased system allowed the user to monitor and store machine variables, and subsequently a Matlab code was used for further signal processing.

3.1. Experimental Results. The $1.1 \mathrm{~kW}$ motor was tested at $1500 \mathrm{rpm}$ and $100 \%$ load in a healthy condition and then under four different phase imbalance voltages of $5,10,15$, 20 , and $25 \mathrm{~V}$; these represented $2 \%, 4 \%, 6 \%, 8 \%$, and $10 \%$, 


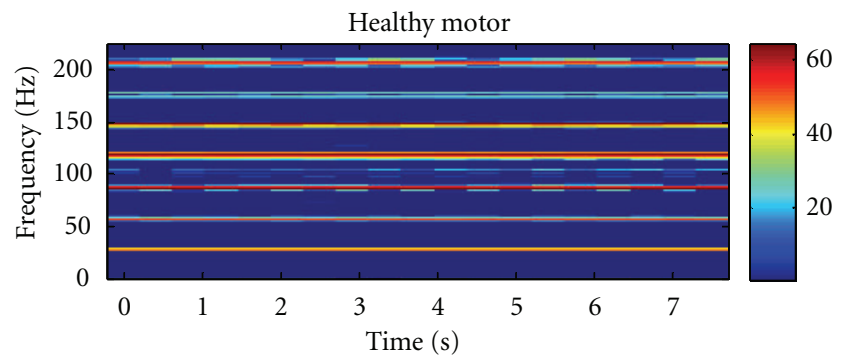

(a)

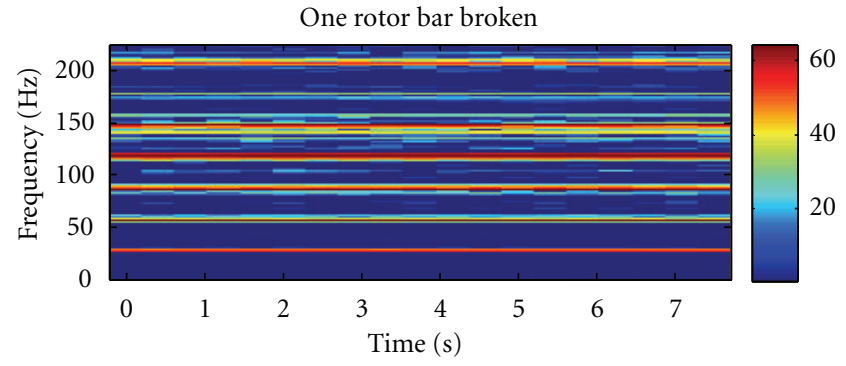

(b)

FIGURE 11: STFT vibration signal from $3 \mathrm{~kW}$ motor with broken rotor bar, $1500 \mathrm{rpm} \mathrm{100 \%} \mathrm{load.}$

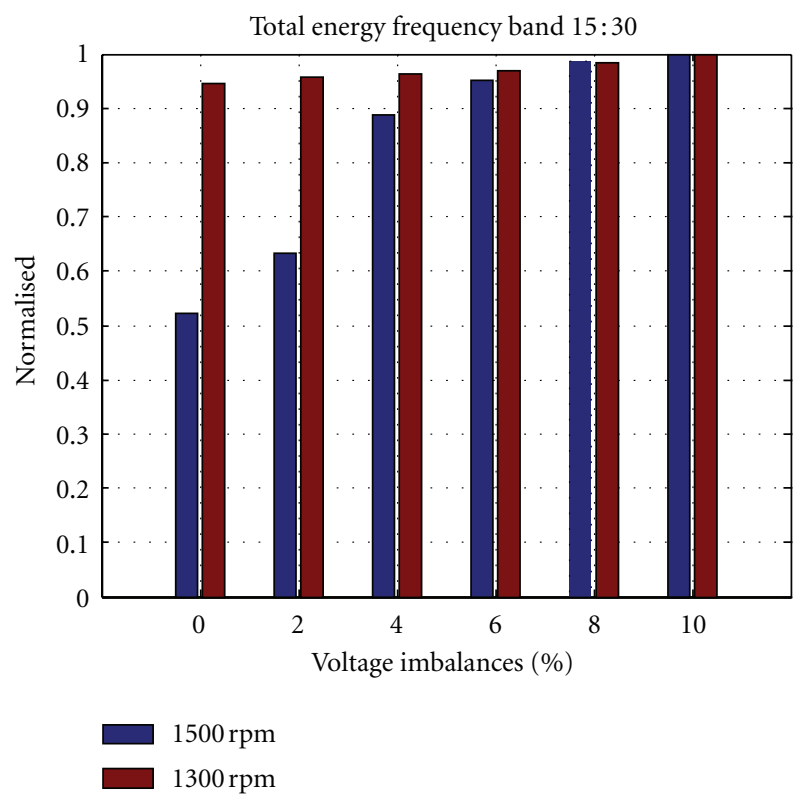

Figure 12: Total energy levels in the frequency band $15-30 \mathrm{~Hz}$, for motor speeds of 1300 and $1500 \mathrm{rpm}$, for voltage imbalance in one phase of the supply, for $1.1 \mathrm{~kW}$ motor at $100 \%$ load.

respectively, of the main nominal voltage level. $1 \mathrm{~mm}$ and $2 \mathrm{~mm}$ motor offset misalignment as shown in Figure 5. The $3 \mathrm{~kW}$ motor was tested at $100 \%$ load in a healthy condition then under two different phase imbalance voltages of 20 and $40 \mathrm{~V}$ and with one rotor bar broken.

A number of statistical parameters (RMS, CF, and kurtosis) were extracted from the measured vibration signal, see Figure 6. No discernible trend or statistically significant differences could be found between the different conditions even in the case of $10 \%$ voltage imbalance.

Where fault 1 and fault 2 are $8 \%$ and $10 \%$, respectively, of the main nominal voltage level. And fault 3 is $2 \mathrm{~mm}$ motor load misalignment.

The measured signals were transformed into the frequency-domain, where the frequencies of their main components were identified, see Figure 7. Three major frequency components were determined within the vibration signal: the first component was at $25 \mathrm{~Hz}$, rotor rotation speed, the second was at $50 \mathrm{~Hz}$, power supply or second harmonic of rotor

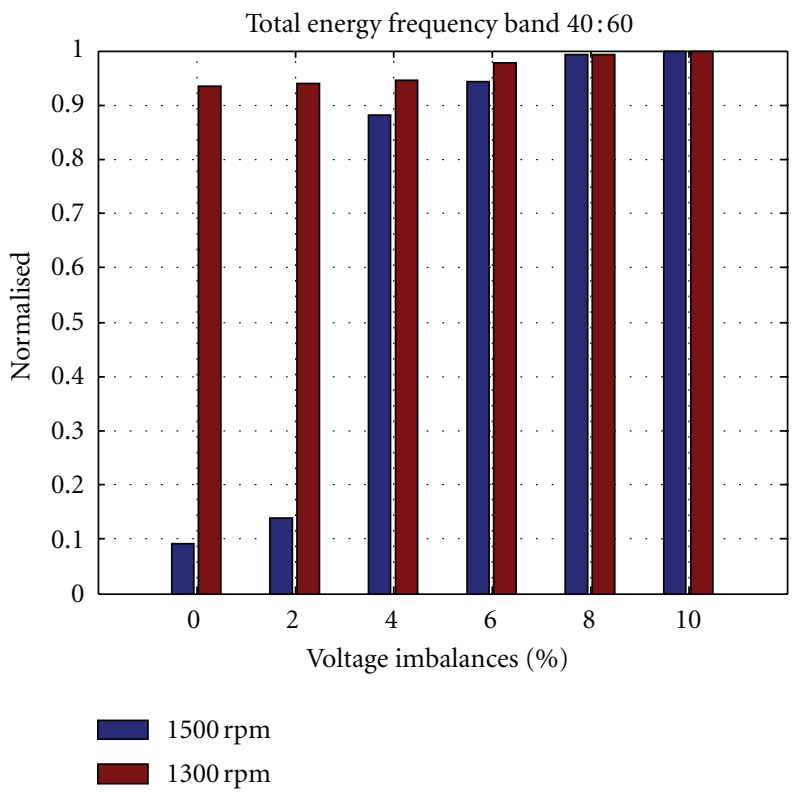

Figure 13: Total energy levels in the frequency band $40-60 \mathrm{~Hz}$, for motor speeds of 1300 and $1500 \mathrm{rpm}$, for voltage imbalance in one phase of the supply, for $1.1 \mathrm{~kW}$ motor at $100 \%$ load.

speed, and the third was at $100 \mathrm{~Hz}$, second harmonic of power supply frequency or fourth harmonic of the rotor frequency. There appears to be a slight increase in the amplitudes of these components between healthy and faults cases, but it was not statistically significant.

Spectral analysis of the measured vibration signal does not provide sufficient information about the motor condition and the severity of the phase imbalance to detect and identify a fault definitively.

In an effort to extract fault severity information the total energy method was applied to the measured vibration signals. Figure 8 presents the STFT analysis of the vibration signal when the $1.1 \mathrm{~kW}$ motor was running at $1500 \mathrm{rpm}$, with various phase imbalances. Figure 9 presents the STFT analysis of the vibration signals when the $1.1 \mathrm{~kW}$ motor was running at $1500 \mathrm{rpm}$ with misalignments of $1 \mathrm{~mm}$ and $2 \mathrm{~mm}$. Figures 10 and 11 present the STFT analysis of the vibration signals when $3 \mathrm{~kW}$ motor running with various 

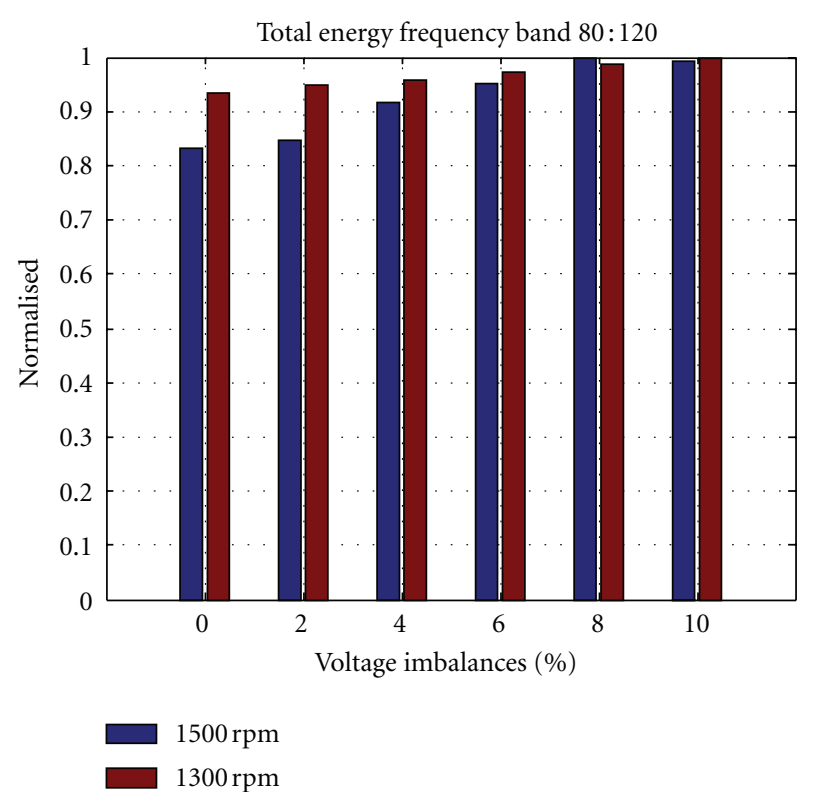

Figure 14: Total energy levels in the frequency band $80-120 \mathrm{~Hz}$, for motor speeds of 1300 and $1500 \mathrm{rpm}$, for voltage imbalance in one phase of the supply, for $1.1 \mathrm{~kW}$ motor at $100 \%$ load.

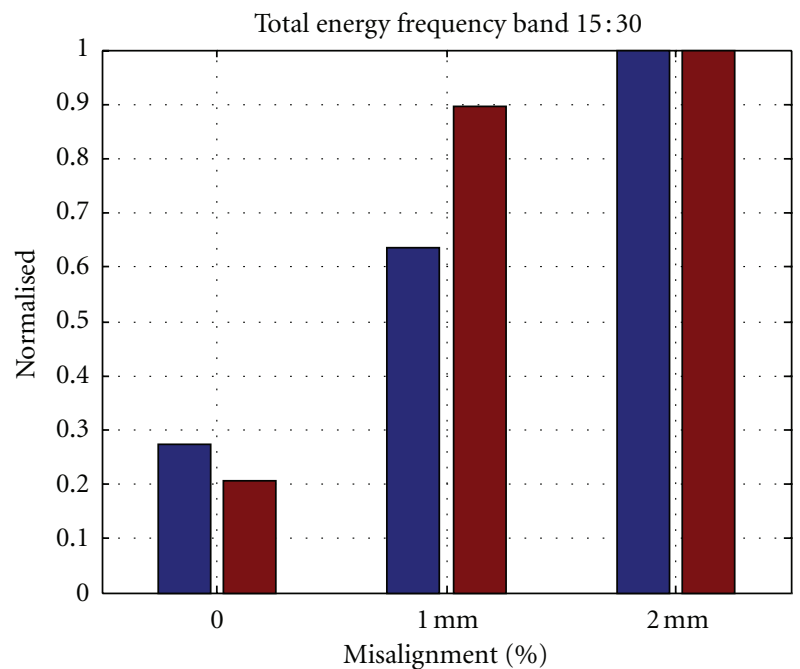

$1500 \mathrm{rpm}$

$1300 \mathrm{rpm}$

Figure 15: Total energy levels in the frequency band $15-30 \mathrm{~Hz}$, for motor speeds of 1300 and $1500 \mathrm{rpm}$, for $1 \mathrm{~mm}$ and $2 \mathrm{~mm}$ misalignment, for $1.1 \mathrm{~kW}$ motor at $100 \%$ load.

voltage imbalances in one phase of the supply and with one rotor broken, respectively.

For the $1.1 \mathrm{~kW}$ motor operating at both 1300 and $1500 \mathrm{rpm}$ the total energy levels were determined for a rotation speed frequency band from 15 to $30 \mathrm{~Hz}$, supply frequency band from 40 to $60 \mathrm{~Hz}$, and twice the power supply frequency band from 80 to $120 \mathrm{~Hz}$. Figures 12, 13, 14, 15, 16 and 17 show the measured total energy for all the cases.

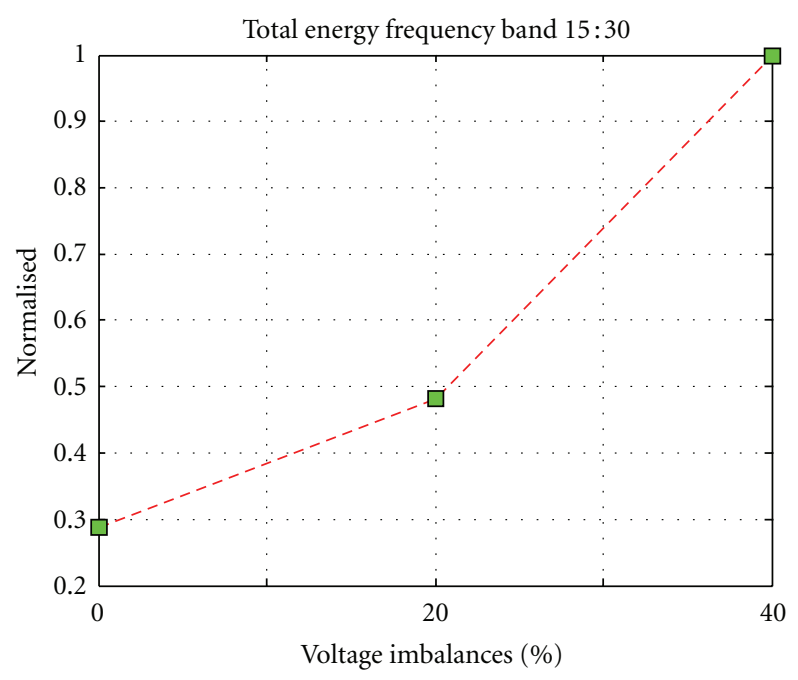

Figure 16: Energy levels in 80 to $120 \mathrm{~Hz}$ frequency band for $3 \mathrm{~kW}$ motor, for voltage imbalance in one phase of the supply speed $1500 \mathrm{rpm}$ at $100 \%$ load.

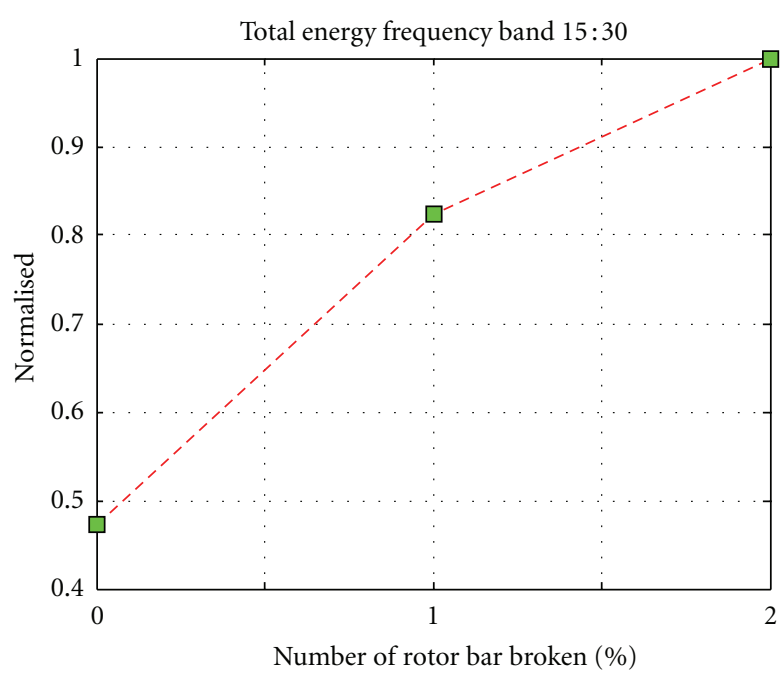

FiguRE 17: Energy levels in $20-30 \mathrm{~Hz}$ frequency band for healthy $3 \mathrm{~kW}$ motor and motor with one and two broken rotor bars, speed $1500 \mathrm{rpm}$ at $100 \%$ load.

In Figure 12 it can be seen that there is a direct relationship between the fault severity and the total energy levels at both speeds for the $1.1 \mathrm{~kW}$ motor. The increase in total energy is particularly apparent at $1300 \mathrm{rpm}$ once the phase imbalance reached $2 \%$. The rate of increase of the total energy at $1500 \mathrm{rpm}$ is much less marked. The same general pattern for voltage phase imbalance can be seen for the frequency bands from 40 to $60 \mathrm{~Hz}$ (Figure 13) and from 80 to $120 \mathrm{~Hz}$ (Figure 14).

Figure 15 shows the total energy under the $15-30 \mathrm{~Hz}$ frequency band for $1 \mathrm{~mm}$ and $2 \mathrm{~mm}$ misalignments. It can be seen that for the $1.1 \mathrm{~kW}$ motor a misalignment of $1 \mathrm{~mm}$ gives a very significant change in the total energy level. Once 
again, however, the response when running at $1500 \mathrm{rpm}$ is nowhere near so marked.

Figures 16 and 17 show the results for phase imbalance and damaged rotor bar, respectively, for the $3 \mathrm{~kW}$ motor running at $1500 \mathrm{rpm}$ and $100 \%$ load.

\section{Conclusion}

A condition-monitoring scheme based on vibration signals measurements and STFT analysis has been successfully applied to a three phase induction motor. The adopted technique of total energy level offers a tool with which to evaluate any abnormality or deviation in the motor processes.

The signal processing procedures developed in this work and their application to measure induction motor vibration signals show promising results in the early detection and diagnosis of faults. The following few conclusions could be highlighted.

(a) Time-domain analysis provided a rough assessment but was not sufficient for fault classification and ranking. Frequency-domain analysis can provide sufficiently detailed spectral information to reveal some hidden features of short duration.

(b) The use of joint time-frequency-domain representation using STFT can extract information about the time domains of different bands of frequencies.

(c) The approach developed here proved to be very good detecting small changes in phase imbalance which make it good condition-monitoring tool for weak signatures.

It is concluded that there can be big advantages in using STFT and total energy level calculations as a fault severity evaluators.

\section{References}

[1] A. Siddique, G. S. Yadava, and B. Singh, "A review of stator fault monitoring techniques of induction motors," IEEE Transactions on Energy Conversion, vol. 20, no. 1, pp. 106-113, 2005.

[2] D. G. Dorrell, W. T. Thomson, and S. Roach, "Analysis of airgap flux, current, and vibration signals as a function of the combination of static and dynamic airgap eccentricity in 3-phase induction motors," IEEE Transactions on Industry Applications, vol. 33, no. 1, pp. 24-34, 1997.

[3] S. Seker, "Determination of air-gap eccentricity in electric motors using coherence analysis," IEEE Power Engineering Review, vol. 20, no. 7, pp. 48-50, 2000.

[4] W. R. Finley, "An analytical approach to solving motor vibration problems," IEEE Transactions on Industry Applications, vol. 36, no. 5, pp. 1467-1480, 2000.

[5] N. Arthur and J. Penman, "Induction machine condition monitoring with higher order spectra," IEEE Transactions on Industrial Electronics, vol. 47, no. 5, pp. 1031-1041, 2000.

[6] B. Liang, A. Ball, and S. Iwnicki, "Asymmetrical stator and rotor fault detection using vibration, per-phase current and transient speed analysis," in Condition Monitoring and Diagnostic Management, chapter 38, p. 329, Elsevier, 2001.
[7] K. Darowicki and A. Zieliński, "Joint time-frequency analysis of electrochemical noise," Journal of Electroanalytical Chemistry, vol. 504, no. 2, pp. 201-207, 2001.

[8] F. Jurado and J. R. Saenz, "Comparison between discrete STFT and wavelets for the analysis of power quality events," Electric Power Systems Research, vol. 62, no. 3, pp. 183-190, 2002.

[9] H. Arabaci and O. Bilgin, "Neural network classification and diagnosis of broken rotor bar faults by means of short time Fourier transform," in Proceedings of the International MultiConference of Engineers and Computer Scientists (IMECS'09), vol. 1, Hong Kong, 2009.

[10] A. Parey, M. El Badaoui, F. Guillet, and N. Tandon, "Dynamic modelling of spur gear pair and application of empirical mode decomposition-based statistical analysis for early detection of localized tooth defect," Journal of Sound and Vibration, vol. 294, no. 3, pp. 547-561, 2006.

[11] P. Vecer, M. Kreidl, and R. Smid, "Condition indicators for gearbox condition monitoring systems," Acta Polytechnica, vol. 45 , no. 6 , pp. 35-43, 2005.

[12] R. Shnibha, A. Albarbar, G. R. Ibrahim, and A. Badri, "Three phase induction motors: phase imbalance severity evaluation based on acoustic measurements and energy calculations," in Proceedings of the Libyan Arab International Conference on Electrical and Electronic Engineering (LAICEEE'10), pp. 32-37, Tripoli, Libya.

[13] I. Ahmed, M. Ahmed, K. Imran, M. S. Kha, T. Akram, and M. Jawad, "Spectral analysis of misalignment in machines using sideband components of broken rotor bar, shorted turns and eccentricity," International Journal of Electrical \& Computer Sciences, vol. 10, no. 06, pp. 85-93, 2010. 

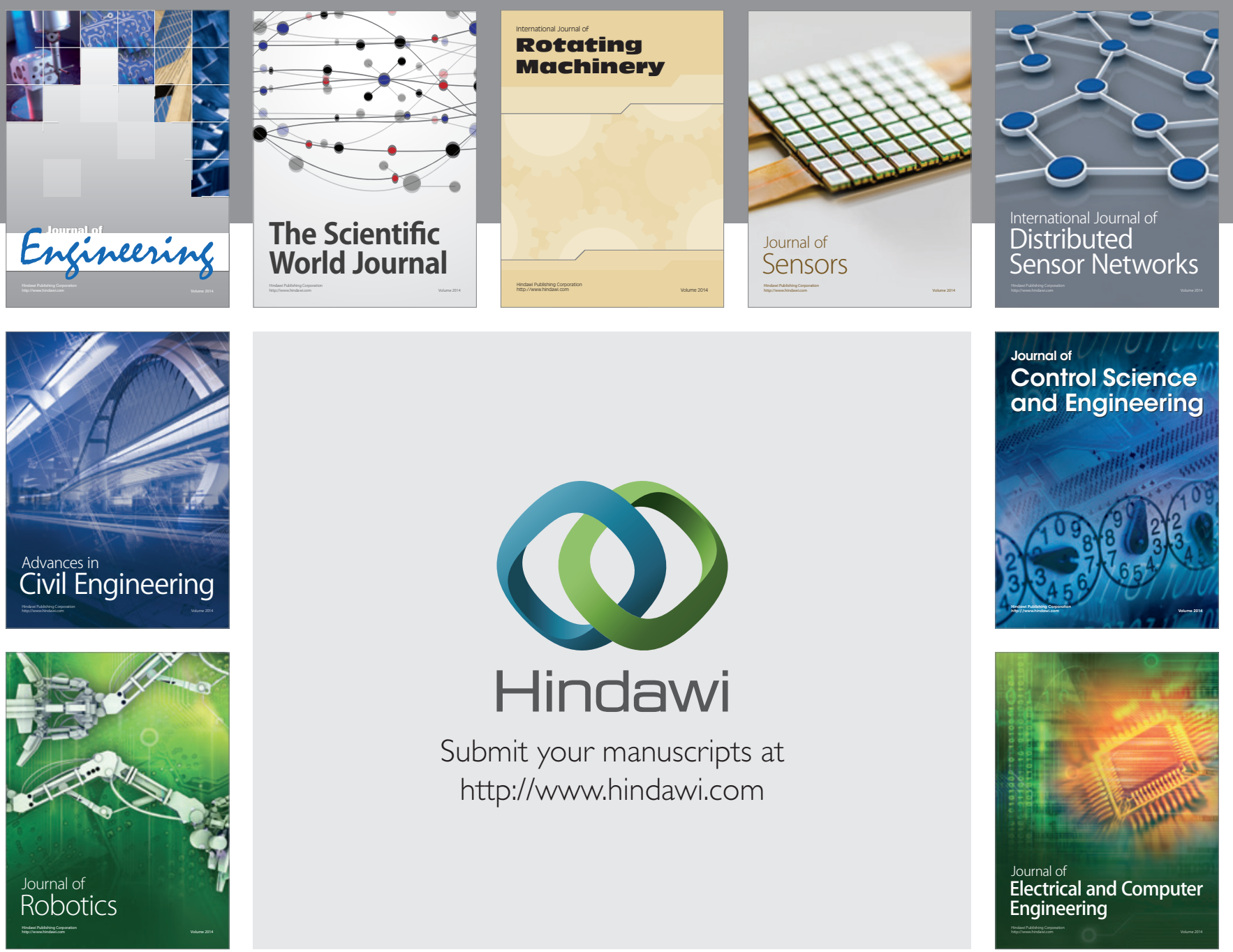

Submit your manuscripts at

http://www.hindawi.com
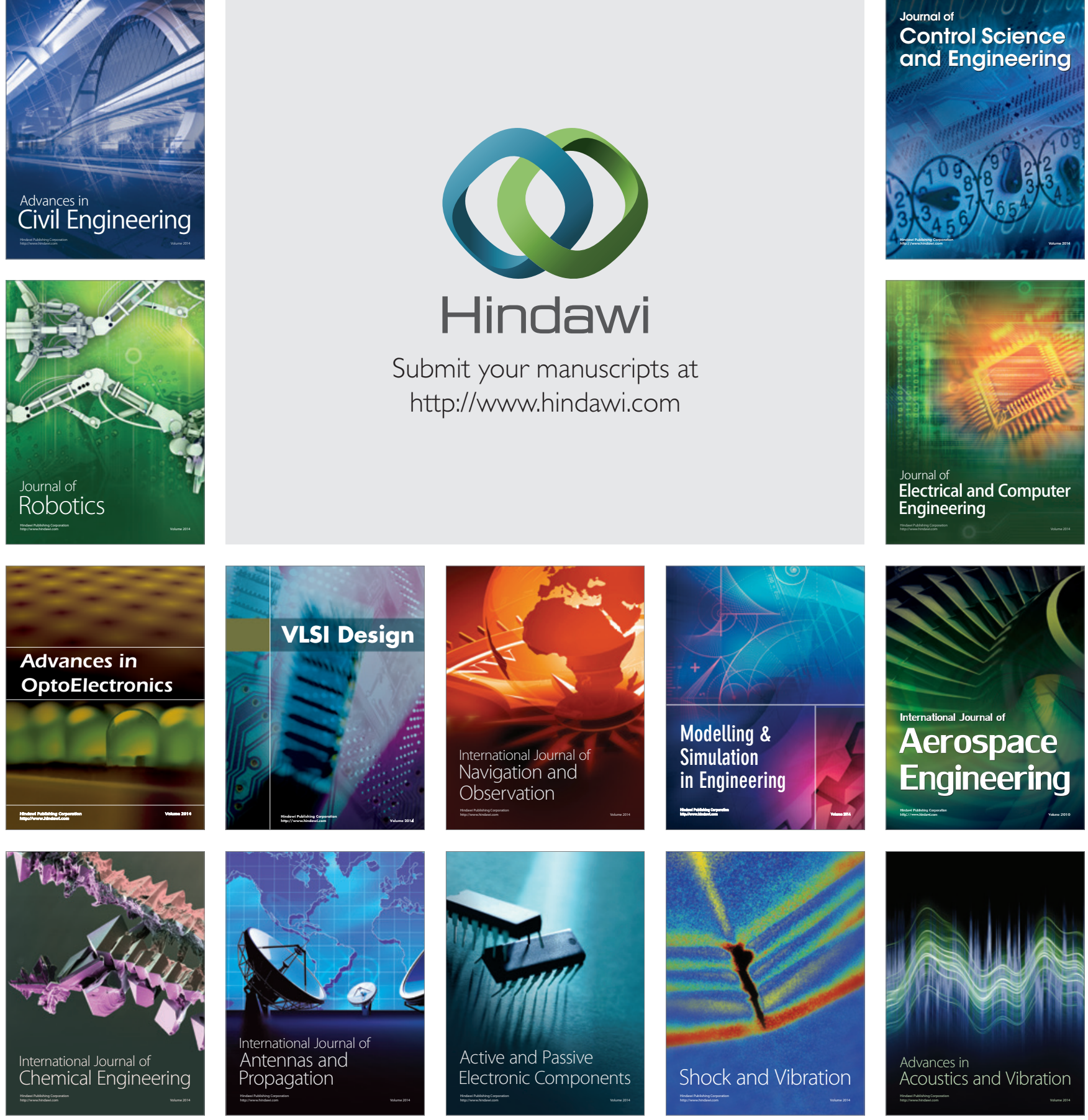